\title{
Pool boiling of ethanol and FC-72 on open microchannel surfaces
}

\author{
Robert Kaniowski ${ }^{1}$, Robert Pastuszko ${ }^{1,{ }^{*}}$ \\ ${ }^{1}$ Kielce University of Technology, Chair of Mechanics, al. 1000-lecia Państwa Polskiego 7, PL-25-314 Kielce, Poland
}

\begin{abstract}
The paper presents experimental investigations into pool boiling heat transfer for open microchannel surfaces. Parallel microchannels fabricated by machining were about $0.3 \mathrm{~mm}$ wide, and 0.2 to $0.5 \mathrm{~mm}$ deep and spaced every $0.1 \mathrm{~mm}$. The experiments were carried out for ethanol, and FC-72 at atmospheric pressure. The image acquisition speed was $493 \mathrm{fps}$ (at resolution $400 \mathrm{x} 300$ pixels with Photonfocus PHOT MV-D1024-160-CL camera). Visualization investigations aimed to identify nucleation sites and flow patterns and to determine the bubble departure diameter and frequency at various superheats. The primary factor in the increase of heat transfer coefficient at increasing heat flux was a growing number of active pores and increased departure frequency. Heat transfer coefficients obtained in this study were noticeably higher than those from a smooth surface.
\end{abstract}

\section{Introduction}

Miniaturization and increasing power of electronic systems requires dissipation of a considerable amount of heat. Modern technology miniaturizes devices and increases their demand for energy. Equipment that generates large heat fluxes is, for example, digital systems, nuclear reactors, internal combustion engines, gas turbines, etc. In the construction of heat exchangers, the aim is to reduce their volume and mass. Pool boiling is a passive cooling technique that allows dissipating large amounts of heat flux at low superheats.

The boiling heat transfer coefficient (HTC) can be further increased by surface modification that involves changing roughness parameters, adding a porous layer, changing the structure of the surface by making small holes in it, and forming microfins or microchannels.

As the practical options of surface structure modification are diverse, the potential for boiling intensification is considerable. Structured surfaces provide higher heat transfer coefficients compared to plain surfaces.

Kalani and Kandlikar [1] used surfaces with open microchannels to investigate pool boiling performance at various channel depths $(245-470 \mu \mathrm{m})$ and widths $(194$ - $406 \mu \mathrm{m}$ ) with ethanol as the working fluid. Microchannels were machined over an area of $10 \times 10$ $\mathrm{mm}^{2}$ in the middle of the $20 \times 20 \mathrm{~mm}^{2}$ test section. The authors concluded that the highest HTC values were obtained for microchannels that were $400 \mu \mathrm{m}$ deep and $200 \mu \mathrm{m}$ wide.

Gheitaghy et al. [2] reported increased HTC on surfaces with inclined minichannels. The experiments were performed with water at atmospheric pressure. Visualization studies carried out on these surfaces indicated increased growing bubble dynamics.
Jaikumar and Kandlikar [3] investigated surfaces with three different interfin channel widths, $300 \mu \mathrm{m}, 500$ $\mu \mathrm{m}$ and $762 \mu \mathrm{m}$, with water at atmospheric pressure. Investigations into the effect of interfin channel width on the performance of the surface and heat transfer mechanisms were conducted on open microchannel surfaces with three coating configurations: sinteredthroughout, sintered-fin-tops, and sintered-channels. The heat transfer coefficients obtained, up to $2900 \mathrm{~kW} / \mathrm{m}^{2} \mathrm{~K}$, were high relative to the structured $10 \times 10 \mathrm{~mm}^{2}$ surface providing about $1000 \mathrm{~kW} / \mathrm{m}^{2} \mathrm{~K}$ relative to the total surface of heat transfer $\left(17 \times 17 \mathrm{~mm}^{2}\right)$.

A. Walunj and A. Sathyabhama [4] studied the effect of a channel shape and geometrical parameters on boiling heat transfer in rectangular, parabolic and stepped microchannels. Microchannels were fabricated on the $10 \mathrm{~mm}$ diameter circular copper test piece. At the heat flux of $100 \mathrm{~kW} / \mathrm{m}^{2}$, the HTC for water increased up to $35 \mathrm{~kW} / \mathrm{m}^{2} \mathrm{~K}$.

Research on pool boiling heat transfer with water, ethanol, FC-72 and Novec-649 from tunnel structures, microfins, microchannels, microcavities [5-10] and boiling heat transfer with FC-72 flowing in narrow channels [11-13] has been conducted at the Kielce University of Technology for more a decade.

The objectives of the present work are to determine the effect of microchannel width on the HTC for ethanol and FC-72 and to identify diameters and frequency of departing bubbles.

\section{Experimental investigations}

The measurements were performed on the setup $[6,14]$ shown in Figs 1 and 2. The setup was designed to allow plotting boiling curves and video recording of the boiling

* Corresponding author: tmprp@tu.kielce.pl 


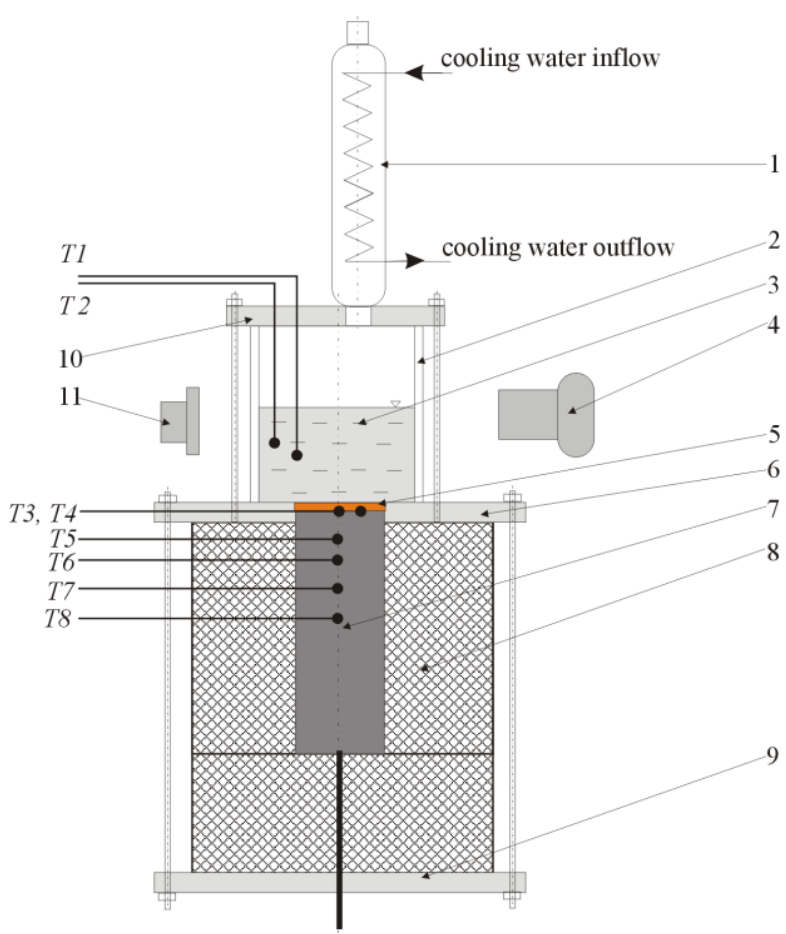

Fig. 1. Main section of pool boiling experimental setup: $1-$ condenser, 2 - glass vessel, 3 - test fluid, 4 - lights, 5 - test surface, 6 - teflon lid, 7 - copper bar with cartridge heater, 8 insulation, 9 - teflon base, 10 - top flange, 11 - high speed camera.

process. From the visualization of boiling, it is possible to determine the diameter of departing vapor bubbles and the frequency of departure from the heat transfer surface. The heat transfer experiments on microchannels were performed under pool boiling conditions, thus the liquid level was more than $50 \mathrm{~mm}$ above the specimen surface. Prior to the measurements, ethanol and FC-72 were degassed by boiling for about 15 minutes. Measurement data were recorded after the stabilization of all temperature values, duration of about $14 \mathrm{~min}$. The heat flux was increased until the boiling crisis was reached. The experiment was performed at atmospheric pressure.

Data reduction was achieved using [6]. Seven K type thermocouples (NiCr-NiAl) were placed in the boiling liquid, under the specimen and in the cylinder. The heat flux, temperature superheat and boiling heat transfer coefficient were related to the level of the micro-fins base. The heat flux was determined from the temperature gradient in the upper part of the heating cylinder, assuming one-dimensional heat conduction.

The base heat transfer coefficient was expressed as:

$$
\alpha=\frac{q}{T_{\mathrm{mb}}-T_{\mathrm{sat}}}=\frac{q}{\Delta T}
$$

The estimated uncertainties were as follows: low heat flux $\left(2 \mathrm{~kW} / \mathrm{m}^{2}\right)$ : heat flux $\pm 35 \%$, heat transfer coefficient $\pm 40 \%$, high heat flux $\left(400 \mathrm{~kW} / \mathrm{m}^{2}\right)$ : heat flux $\pm 2.4 \%$, heat transfer coefficient $\pm 2.7 \%$.

The images of the bubbles at nucleation, growth and departure were obtained using a PHOT MV-D1024-160CL (Photonfocus) digital monochromatic camera with a resolution of $1024 \times 758$ pixels.

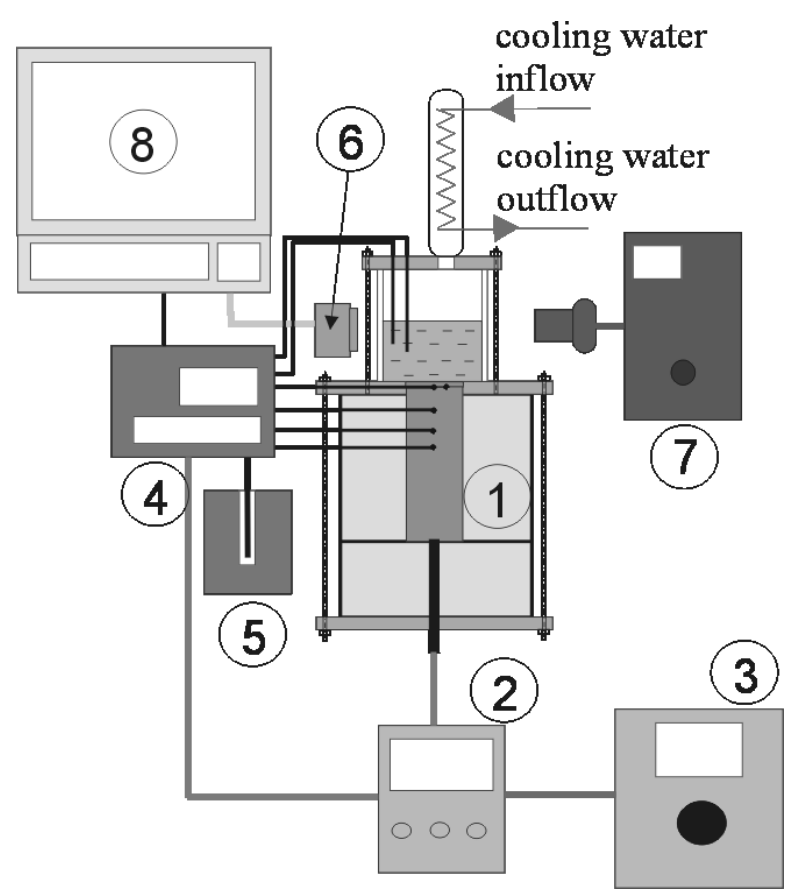

Fig. 2. Pool boiling measurement setup: 1 - main section, $2-$ wattmeter, 3 - autotransformer, 4 - data logger, 5 - dry-well calibrator, 6 - high speed camera, 7 -lights, 8 - PC.

The camera recorded the photos at a speed of $428 \mathrm{fps}$ at a resolution of $500 \times 250$ pixels and the mean error of 2 fps. An EX-FH20 (Casio) camera was used to record the images of the entire surface of the specimen. Lighting was provided by a halogen lamp with light pipes (front light and back light).

The images of the bubbles at nucleation, growth and departure were obtained using a PHOT MV-D1024-160CL (Photonfocus) digital monochromatic camera with a resolution of $1024 \times 758$ pixels. The camera recorded the photos at a speed of $428 \mathrm{fps}$ at a resolution of $500 \times 250$ pixels and the mean error of $2 \mathrm{fps}$. An EX-FH20 (Casio) camera was used to record the images of the entire surface of the specimen. Lighting was provided by a halogen lamp with light pipes (front light and back light).

The diameters and departure frequencies were determined as the average value from 10 nucleation sites for 30 consecutive vapor bubbles. Bubble diameters were measured in two directions and the arithmetic mean was determined at a constant heat flux. The absolute error of bubble diameter measurement was 2 pixels, i.e., $0.2 \mathrm{~mm}[7]$.

The specimens with test surfaces were made of copper and had parallel grooves with a constant pitch, made with a end mill of $0.3 \mathrm{~mm}$ in diameter (CNC machining process), Fig.3. The test section consists of a $32.5 \times 32.5 \mathrm{~mm}^{2}$ square copper specimen with a $26.8 \mathrm{x}$ $26.8 \mathrm{~mm}^{2}$ boiling region. Figure $3 \mathrm{a}$ shows a magnification of the microchannels. The mean roughness of the microchannel surface was $0.127 \mu \mathrm{m}$. Table 1 compiles the surface codes and specifications according to Fig. $3 b$. 
a)

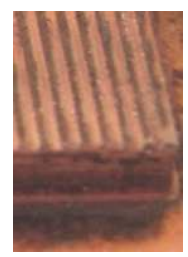

MC-0.3-0.2-0.6

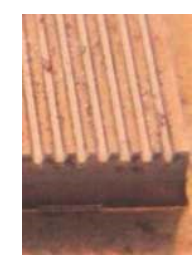

MC-0.3-0.3-0.6
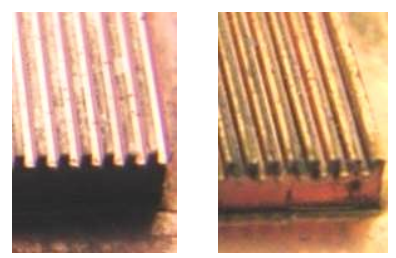

MC-0.3-0.5-0.6

b)

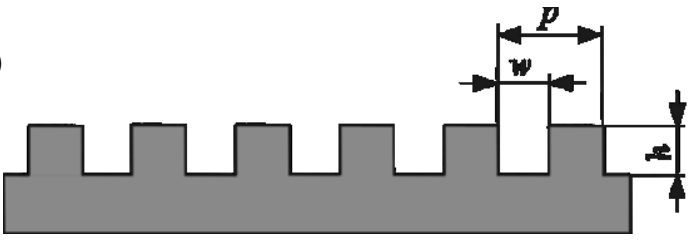

Fig. 3. a) View of the specimen, b) dimension symbols.

Table 1. Surface codes and specifications.

\begin{tabular}{|c|c|c|c|}
\hline Specimen code & $\begin{array}{c}w \\
\mathrm{~mm}\end{array}$ & $\begin{array}{c}h \\
\mathrm{~mm}\end{array}$ & $\begin{array}{c}p \\
\mathrm{~mm}\end{array}$ \\
\hline MC-0.3-0.5-0.6 & 0.3 & 0.5 & 0.6 \\
\hline MC-0.3-0.4-0.6 & 0.3 & 0.4 & 0.6 \\
\hline MC-0.3-0.3-0.6 & 0.3 & 0.3 & 0.6 \\
\hline MC-0.3-0.2-0.6 & 0.3 & 0.2 & 0.6 \\
\hline
\end{tabular}

\section{Results}

Figures $4 \mathrm{a}$ and $4 \mathrm{~b}$ show the relationship between the heat flux and temperature superheat on MC surfaces for boiling ethanol and FC-72. The data for ethanol was taken from [14].

Table 2 summarizes calculation results of constant $C$ and exponent $n$ at $q=C \Delta T^{n}$ for ethanol and FC-72 on four MC surfaces and one smooth surface.

A slight heat transfer enhancement was observed on the MC surfaces compared to smooth surface (ethanol). The heat transfer coefficient was independent of the microchannel depth. Of the samples tested, the best results were recorded for MC-0.3-0.3-0.6, where the heat transfer coefficient was $20.3 \mathrm{~W} / \mathrm{m}^{2} \mathrm{~K}$ at a superheat of 15.7 K. With FC-72, a significant heat transfer increase was attained by MC-0.3-0.5-0.6 $\left(\alpha=9.8 \mathrm{~W} / \mathrm{m}^{2} \mathrm{~K}\right.$ at $\Delta T \approx 9.3 \mathrm{~K}$ ).

Figures 5 and 6 illustrate nucleate boiling of ethanol and FC-72 respectively on the surface with microchannels at increasing atmospheric pressure. With ethanol, small vapor bubbles formed, all of approximately $0.5 \mathrm{~mm}$ in size, at a low heat flux of about $10 \mathrm{~kW} / \mathrm{m}^{2}$. The nucleation sites located at the bottom of the microchannels, spread over their entire lengths, were active uninterruptedly, and their influence areas did not overlap. Similar phenomena were observed for FC-72. For higher heat flux $\left(q>20 \mathrm{~kW} / \mathrm{m}^{2}\right.$ ethanol $)$ and $\left(q>7 \mathrm{~kW} / \mathrm{m}^{2}\right.$ FC-72), the bubble diameters and frequency stabilized taking the values $d_{b}=2.2 \mathrm{~mm}$ (dash line), $f=70 \mathrm{~Hz}$ for ethanol and $d_{b}=1.4 \mathrm{~mm}$ (dash line), $f$ $=105 \mathrm{~Hz}$ for FC-72, Figs 7, 8. Most centers were active during the entire cycle of increasing heat flux, producing bubbles continuously. The bubbles started to coalesce

both before departure (horizontal coalescence) and after departure (vertical coalescence). The bubbles developed funnel-like shapes, extending in the lower part. For $q>$ $58 \mathrm{~kW} / \mathrm{m}^{2}$ (ethanol) and $q>18 \mathrm{~kW} / \mathrm{m}^{2}$ (FC-72), quantitative observations became impossible due to the bubbles obscuring the image by coalescing and forming vapor tunnels.

Heat flux/diameter and heat flux/frequency relationships for ethanol and FC-72 are illustrated in Figs 7 and 8 respectively.

The authors proposed calculating the departing bubble diameter for the open microchannel on the basis of buoyancy force and surface tension balance referred to the incircle diameter of the microchannel space. It was also assumed that the contact angle was $90^{\circ}$, and inertia forces and lift force were neglected. The departing bubble diameter dependence can be calculated from the formula:

$$
d_{b}=\left(\frac{6 \sigma w}{g\left(\rho_{l}-\rho_{v}\right)}\right)^{1 / 3}
$$

For the microchannel width $\mathrm{w}=0.3 \mathrm{~mm}$, the calculated values $d_{b}=1.6 \mathrm{~mm}$ and $d_{b}=1.0 \mathrm{~mm}$ for ethanol and FC-72, respectively, are lower than the described earlier stabilized diameters of about $28 \%$ (Fig. $5)$.

a)
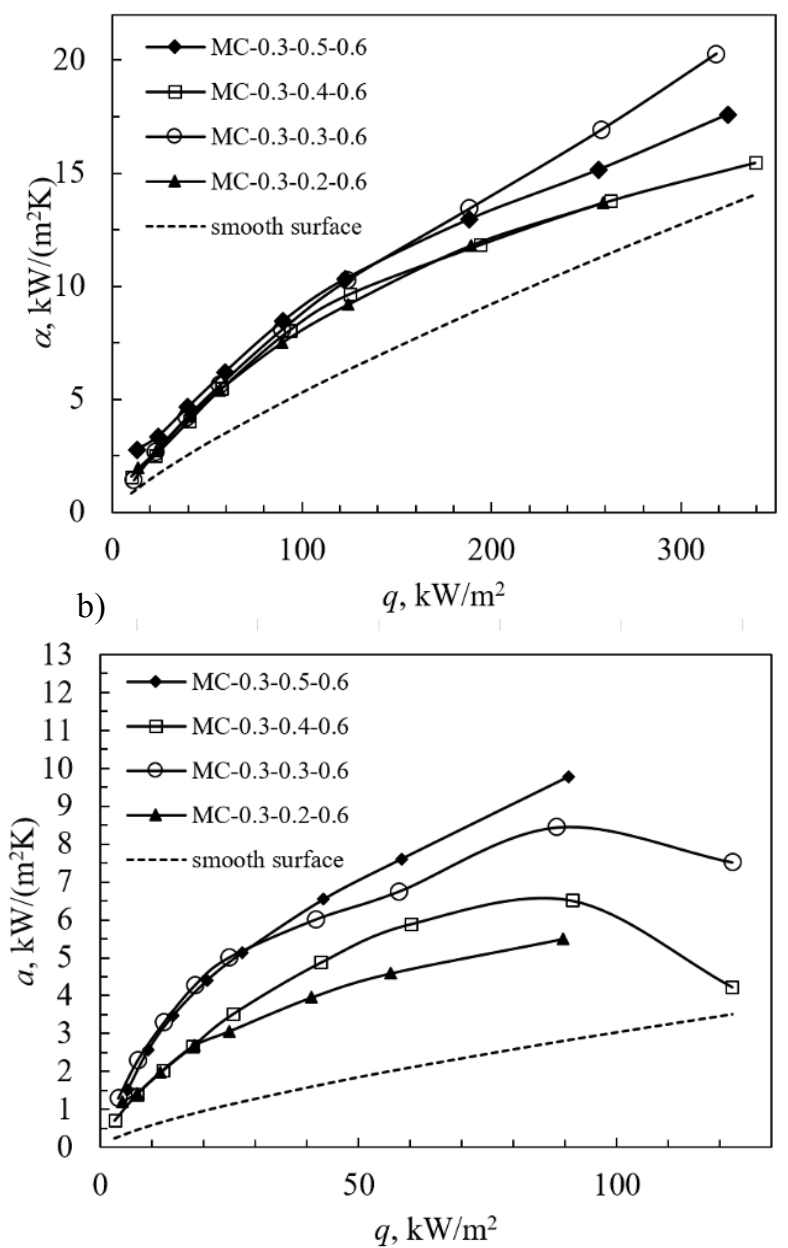

Fig. 4. Heat transfer coefficient vs. heat flux, a) ethanol, b) FC72 . 
Table 2. Constant $\mathrm{C}$ and exponent $\mathrm{n}$ as a function of $q(\Delta T)$

\begin{tabular}{|c|c|c|c|}
\hline Specimen code & fluid & $C$ & $n$ \\
\hline MC-0.3-0.2-0.6 & ethanol & 0.036 & 3.09 \\
\hline MC-0.3-0.3-0.6 & ethanol & 0.047 & 2.96 \\
\hline MC-0.3-0.4-0.6 & ethanol & 0.002 & 4.45 \\
\hline MC-0.3-0.5-0.6 & ethanol & 0.220 & 2.50 \\
\hline Smooth surface & ethanol & 0.001 & 5.00 \\
\hline MC-0.3-0.2-0.6 & FC-72 & 0.302 & 2.08 \\
\hline MC-0.3-0.3-0.6 & FC-72 & 0.574 & 2.20 \\
\hline MC-0.3-0.4-0.6 & FC-72 & 0.078 & 2.81 \\
\hline MC-0.3-0.5-0.6 & FC-72 & 0.305 & 2.61 \\
\hline Smooth surface & FC-72 & 0.001 & 3.57 \\
\hline
\end{tabular}

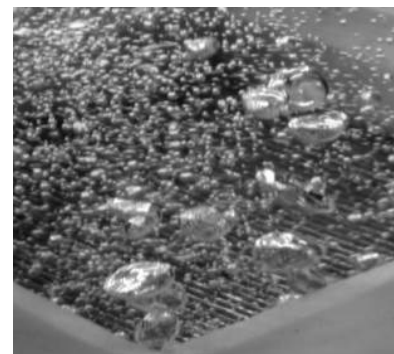

(a) $q=10 \mathrm{~kW} / \mathrm{m}^{2}$

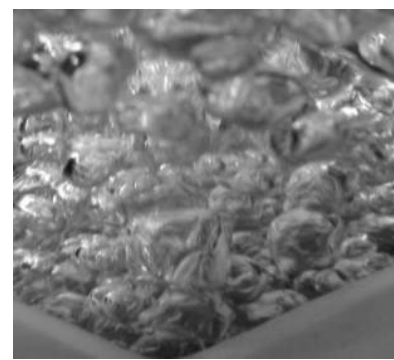

(c) $q=40.4 \mathrm{~kW} / \mathrm{m}^{2}$

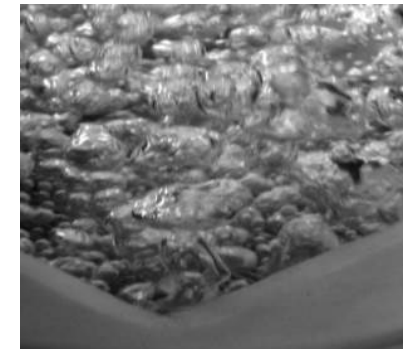

(b) $q=22.6 \mathrm{~kW} / \mathrm{m}^{2}$

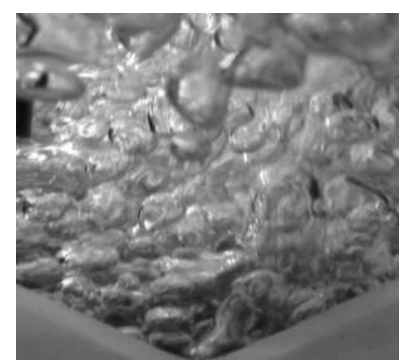

(d) $q=57,8 \mathrm{~kW} / \mathrm{m}^{2}$
Fig. 5. Visualization observations of pool boiling of ethanol on the microchannel surface MC-0.3-0.4-0.6.

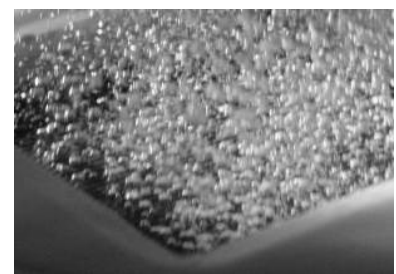

(a) $q=2.8 \mathrm{~kW} / \mathrm{m}^{2}$

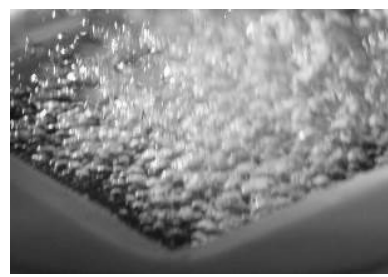

(c) $q=12.1 \mathrm{~kW} / \mathrm{m}^{2}$

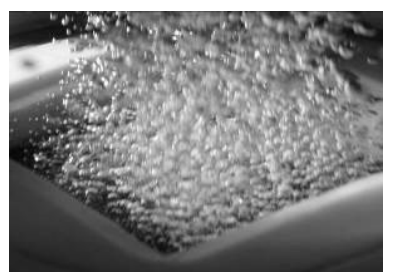

(b) $q=7.1 \mathrm{~kW} / \mathrm{m}^{2}$

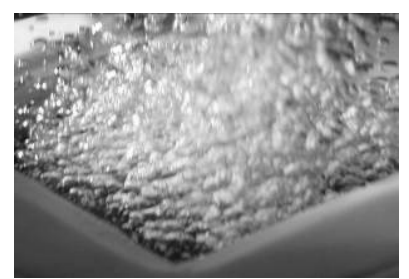

(d) $q=17.9 \mathrm{~kW} / \mathrm{m}^{2}$
Fig. 6. Visualization observations of pool boiling of FC-72 on the microchannel surface MC-0.3-0.4-0.6. a)
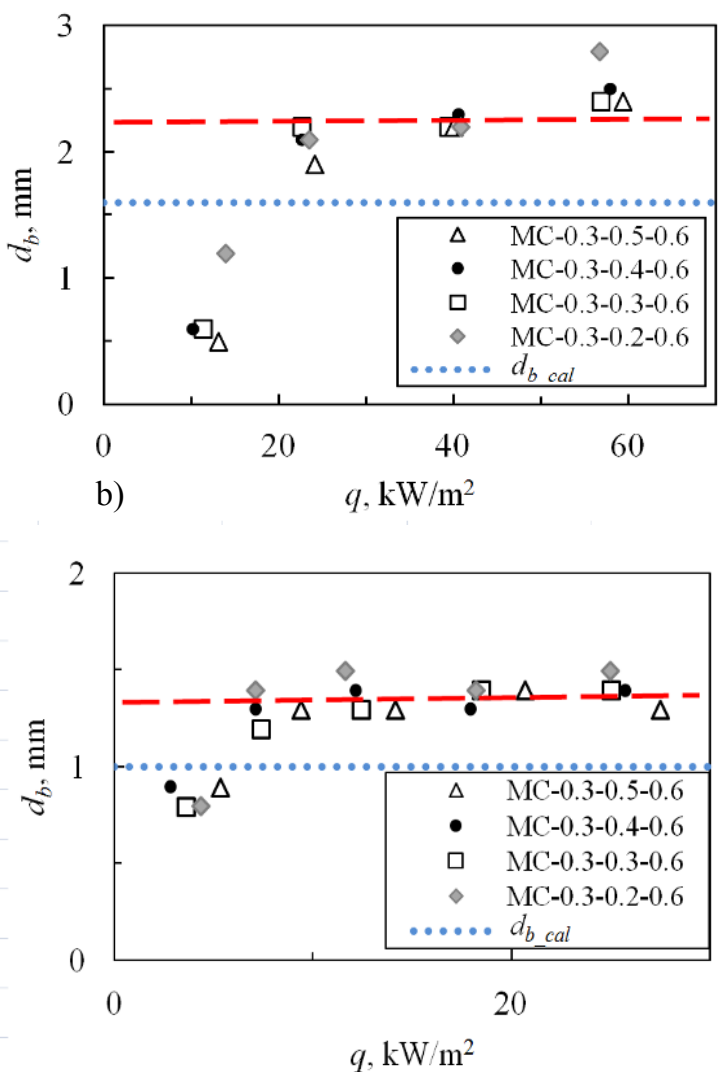

Fig. 7. Averaged diameters for (a) ethanol, (b) FC-72, theoretical value $d_{b}$ cal was calculated from eq. 2 .
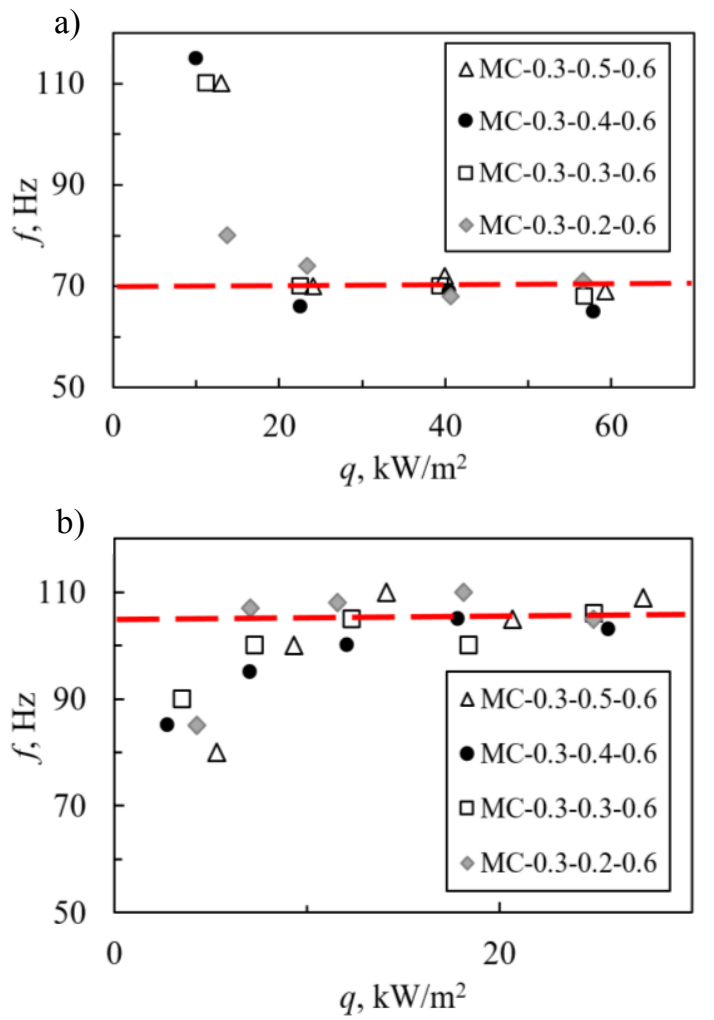

Fig. 8. Averaged frequencies for (a) ethanol, (b) FC-72. 


\section{Conclusions}

The experimental studies discussed in this paper led to the following conclusions:

- HTC on surfaces with best performance were two times higher for ethanol and more than three times higher for FC-72 than HTC for plain surfaces.

- For small superheats between the heating surface and the liquid, vapor bubbles take spherical shapes and do not coalesce. At larger superheats, the bubbles interact strongly forming vapor tunnels.

- Bubble diameters and departure frequencies became stable after reaching the limit of $20 \mathrm{~kW} / \mathrm{m}^{2}$ with ethanol and $7 \mathrm{~kW} / \mathrm{m}^{2}$ with FC-72.

- Experimental studies for other liquids, channel widths and pitches are necessary to check the effect of at least three geometrical parameters on the heat transfer process.

\section{Nomenclature}

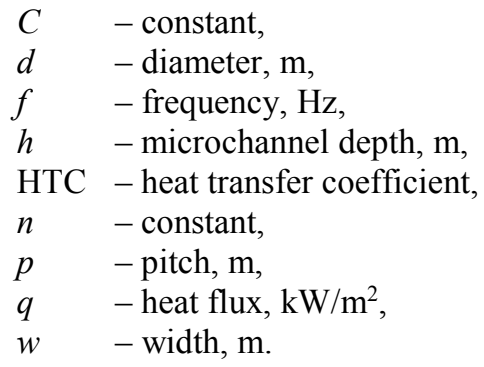

\section{Greek symbols}

$\alpha \quad$ - heat transfer coefficient (HTC), W/( $\left.\mathrm{m}^{2} \mathrm{~K}\right)$,

$\Delta T$ - difference of temperature, $\mathrm{K}$,

$\rho \quad-$ density, $\mathrm{kg} / \mathrm{m}^{3}$,

$\sigma \quad-$ surface tension, $\mathrm{N} / \mathrm{m}$,

\section{Subscripts}

$$
\begin{array}{ll}
b & \text { - bubble, } \\
c a l & \text { - calculated, } \\
l & \text { - liquid, } \\
\mathrm{mb} & \text { - microchannel base (bottom), } \\
\mathrm{sat} & \text { - saturation, } \\
v & \text { - vapor. }
\end{array}
$$

\section{References}

1. Kalani A., Kandlikar S.G., proc. ASME 10th Int. Conf. Nanochannels, Microchannels and Minichannels, Rio Grande, Puerto Rico (2012)

2. A. M. Gheitaghy, A. Samimi, H. Saffari, Appl. Therm. Eng. 126 (2017)

3. A. Jaikumar, S. G. Kandlikar, Int. J. Heat and Mass Transfer 95 (2016)

4. A. Walunj, A. Sathyabhama, Appl. Therm. Eng. 128 (2018)

5. R. Pastuszko, R. Kaniowski, EPJ Web of Conferences, 25, 02019 (2012)

6. R. Pastuszko, EPJ Web of Conferences 114, 01002 (2016)

7. R. Kaniowski, R. Pastuszko, L. Nowakowski, EPJ Web of Conferences 143, 02049 (2017)

8. R. Pastuszko, EPJ Web of Conferences 45, 01020 (2013)

9. R. Pastuszko, M. Piasecka, Journal of Physics: Conference Series 395, 012137 (2012)

10. R. Pastuszko, M.E. Poniewski, M. Koziol, Heat Mass Transfer, 48 (2012)

11. S. Hozejowska, R. Kaniowski, M. Poniewski, Exp. Therm. Fluid Sci.78 (2016)

12. M. Piasecka, K. Strak, B. Grabas, Arch. Metall. Mater. 62 (2017)

13. M. Piasecka, K. Strak, B. Maciejewska, Heat Transf. Eng. 38 (2017)

14. R. Kaniowski, R. Pastuszko, Proc. XXIII Convention of Thermodynamics Researchers, Beskid Śląski, Poland, 2017 